ARTICLE

https://doi.org/10.1038/s41467-019-12678-5

\title{
Ba-induced phase segregation and band gap reduction in mixed-halide inorganic perovskite solar cells
}

\author{
Wanchun Xiang ${ }^{1,2,8 *}$, Zaiwei Wang (10) 2,8, Dominik J. Kubicki ${ }^{3,4,7}$, Xueting Wang ${ }^{5}$, Wolfgang Tress (iD) ${ }^{2}$, \\ Jingshan Luo (1) 3,6, Jiahuan Zhang ${ }^{2}$, Albert Hofstetter (1) 4, Lijun Zhang (1) 5, Lyndon Emsley ${ }^{4}$, Michael Grätzel ${ }^{3}$ \& \\ Anders Hagfeldt (D) ${ }^{2 \star}$
}

All-inorganic metal halide perovskites are showing promising development towards efficient long-term stable materials and solar cells. Element doping, especially on the lead site, has been proved to be a useful strategy to obtain the desired film quality and material phase for high efficient and stable inorganic perovskite solar cells. Here we demonstrate a function by adding barium in $\mathrm{CsPb}_{2} \mathrm{Br}$. We find that barium is not incorporated into the perovskite lattice but induces phase segregation, resulting in a change in the iodide/bromide ratio compared with the precursor stoichiometry and consequently a reduction in the band gap energy of the perovskite phase. The device with 20 mol\% barium shows a high power conversion efficiency of $14.0 \%$ and a great suppression of non-radiative recombination within the inorganic perovskite, yielding a high open-circuit voltage of $1.33 \mathrm{~V}$ and an external quantum efficiency of electroluminescence of $10^{-4}$.

\footnotetext{
${ }^{1}$ State Key Laboratory of Silicate Materials for Architectures, Wuhan University of Technology, 430070 Wuhan, China. ${ }^{2}$ Laboratory of Photomolecular Science, Institute of Chemical Sciences Engineering, Ecole Polytechnique Fedérale de Lausanne (EPFL), 1015 Lausanne, Switzerland. ${ }^{3}$ Laboratory of Photonics and Interfaces, Institute of Chemical Sciences and Engineering, Ecole Polytechnique Fedérale de Lausanne (EPFL), CH-1015 Lausanne, Switzerland. ${ }^{4}$ Laboratory of Magnetic Resonance, Institute of Chemical Sciences and Engineering, Ecole Polytechnique Fedérale de Lausanne (EPFL), CH-1015 Lausanne, Switzerland. ${ }^{5}$ State Key Laboratory of Superhard Materials, Key Laboratory of Automobile Materials of MOE, and School of Materials Science and Engineering, Jilin University, Changchun 130012, China. ${ }^{6}$ Institute of Photoelectronic Thin Film Devices and Technology, Key Laboratory of Photoelectronic Thin Film Devices and Technology of Tianjin, Nankai University, 300350 Tianjin, China. ${ }^{7}$ Present address: Cavendish Laboratory, JJ Thomson Avenue, Kapitza Building K26, Cambridge CB3 OHE, UK. ${ }^{8}$ These authors contribute equally: Wanchun Xiang, Zaiwei Wang. *email: xiangwanchun@whut.edu.cn; anders.hagfeldt@epfl.ch
} 
ead halide perovskites have the advantage of relatively high charge carrier diffusion lengths, high light harvesting efficiency, and band gap $\left(E_{\mathrm{g}}\right)$ tunability, making them ideal materials for photovoltaic applications ${ }^{1}$. In 10 years, the certified power conversion efficiency (PCE) of perovskite solar cells (PSCs) has reached $25.2 \%$, which is higher than that of polycrystalline silicon solar cells ${ }^{2-6}$. Despite these advances, the use of organic components (e.g., methylammonium and formamidinium) in perovskite materials generates stability concerns due to the volatility of the organic components ${ }^{7-10}$. Therefore, the development of all-inorganic perovskites for photovoltaic devices is currently extensively explored, as the replacement of organic components by their inorganic counterpart $\left(\mathrm{Cs}^{+}\right)$could solve the stability issue $\mathrm{e}^{1,12}$.

Nevertheless, the inorganic lead halide PSCs are still facing large challenges in the improvement of PCE and phase stability, due to large $E_{\mathrm{g}}(1.7 \mathrm{eV}$ to $2.3 \mathrm{eV})$ relative to the ideal $E_{\mathrm{g}}$ of $\sim 1.3 \mathrm{eV}$ for single-junction solar cells ${ }^{13,14}$, and instability of the cubic phase or black phase for I-based narrow band gap inorganic perovskites ${ }^{15,16}$. Element doping, especially on the lead site, has been proved to be a useful strategy to solve the above problems, as well as reduce the usage amount of toxic lead ${ }^{17}$. For example, $\mathrm{Sn}^{2+}$ and $\mathrm{Ge}^{2+}$, belonging to the same (IV) group as $\mathrm{Pb}^{2+}$, seem to be the most promising candidates to replace $\mathrm{Pb}^{2+}$, while also exhibiting band gap tunability ${ }^{18,19}$. However, the fast oxidation of $\mathrm{Sn}^{2+}$ and $\mathrm{Ge}^{2+}$ when exposed to ambient atmosphere limits the fabrication of Sn/Ge-based PSCs to inert environments ${ }^{20}$. Other divalent cations such as $\mathrm{Mn}^{2+}, \mathrm{Sr}^{2+}, \mathrm{Eu}^{2+}$, etc., have been explored as dopants for inorganic perovskites ${ }^{15,21-24}$, but they are generally at low doping ratios (typically around $5 \%$ on the lead site) and do not alter the band gap substantially. In addition, there is no consensus in terms of whether these cations are being incorporated into the perovskite lattice and the exact action mechanism of these dopants to improve the PSC performance is still under debate ${ }^{25}$.

Here we show that barium can be added in large quantities (the molar ratio of barium and lead up to $4: 6$ in the perovskite precursor solutions) during the synthesis of the inorganic $\mathrm{CsPbI}_{2} \mathrm{Br}$ perovskite, leading to the reduction of the perovskite band gap. The open-circuit voltage $\left(V_{\mathrm{OC}}\right)$ of the inorganic PSCs with the addition of $20 \mathrm{~mol} \%$ barium to the precursor solution is significantly improved to $1.33 \mathrm{~V}$, yielding a PCE of $14.0 \%$. To the best of our knowledge, this is the highest reported $V_{\mathrm{OC}}$ for allinorganic PSCs with a band gap lower than $2 \mathrm{eV}$. Solid-state nuclear magnetic resonance (NMR) measurements evidence that there is no incorporation of barium into the perovskite lattice. Rather, barium segregates into barium-based non-perovskite phases with concomitant halide segregation. As a consequence, the perovskite phase is enriched in iodide, leading to changes in the lattice parameter and band gap compared with the undoped $\mathrm{CsPb}_{2} \mathrm{Br}$. The I-rich perovskite acts as the light-harvesting species and its band gap is linearly dependent on the amount of added barium, whereas the barium-based non-perovskite phases prohibit non-radiative recombination and are responsible for the high $V_{\text {OC. }}$

\section{Results}

Perovskite characterizations and device performance. The perovskite precursor solutions were prepared by mixing CsI, $\mathrm{PbI}_{2}$, $\mathrm{PbBr}_{2}, \mathrm{CsBr}$, and $\mathrm{BaI}_{2}$ in the required stoichiometric molar ratios in anhydrous dimethylsulfoxide (DMSO). The perovskite films were deposited from precursor solutions on mesoporous $\mathrm{TiO}_{2}$ substrates at a spinning speed of 3000 r.p.m. with the conventional one-step spin-coating method. The films were subsequently annealed at $280^{\circ} \mathrm{C}$ for $10 \mathrm{~min}$ in dry air. For convenience, we refer to these films using their precursor solution stoichiometry: $\mathrm{CsPb}_{1-x} \mathrm{Ba}_{x} \mathrm{I}_{2} \mathrm{Br}$ ( $x=0$ to 1$)$. Supplementary Fig. 1 shows the photographs of these perovskite films for different barium concentration. The color of the films gradually changes from dark into light brown as the barium fraction is increased. The pure $\mathrm{CsBaI}_{2} \mathrm{Br}$ film is colorless, confirming negligible absorption of visible light. Therefore, in the following we restrict ourselves to barium molar fraction $x \leq 0.4$ for PSCs fabrication.

We first investigated the X-ray diffraction (XRD) of the $\mathrm{CsPb}_{1-x} \mathrm{Ba}_{x} \mathrm{I}_{2} \mathrm{Br}(x=0$ to 0.4$)$ thin films. The XRD patterns are shown in Supplementary Fig. 2. The addition of barium resulted in a gradual decrease of the perovskite peak intensities (diagnostic peaks: $14.5^{\circ}, 21.1^{\circ}, 29.7^{\circ}$ ), which can still be reserved for $x \leq 0.4$. A close scrutiny of the reflection peaks (Fig. 1a) revealed a noticeable shift to lower angles. According to the Bragg's law, the low-angle shift reflects an expansion of the unit-cell volume ${ }^{13}$. Its effect on the optoelectronic properties was further examined by ultraviolet-visible (UV-vis) spectroscopy (Fig. 1b). We found a significant shift in the absorption onset to longer wavelength with increasing barium concentration. Meanwhile, a gradual decrease of the absorption intensity with constant film thickness indicates that the introduction of barium leads to a deterioration of the light-harvesting capacity. An analogous red-shift trend was observed in photoluminescence (PL) emission spectra (Fig. 1c). These results show that the introduction of barium alters the band gap of the parent $\mathrm{CsPbI}_{2} \mathrm{Br}$ perovskite.

The $\mathrm{Ba}-\mathrm{Pb}$ mixed perovskites were then used to fabricate allinorganic PSCs in the following device configuration: F-doped tin oxide (FTO) glass/compact- $\mathrm{TiO}_{2} /$ mesoporous $\mathrm{TiO}_{2} / \mathrm{CsPb}_{1-x}$ $\mathrm{Ba}_{x} \mathrm{I}_{2} \mathrm{Br} / 2,2^{\prime}, 7,7^{\prime}$-tetrakis(N,N-di-p-methoxyphenyl-amine) 9,9'spirobifluorene (Spiro-OMeTAD)/Au (for the cross-sectional scanning electron microscope (SEM) image of a complete device,
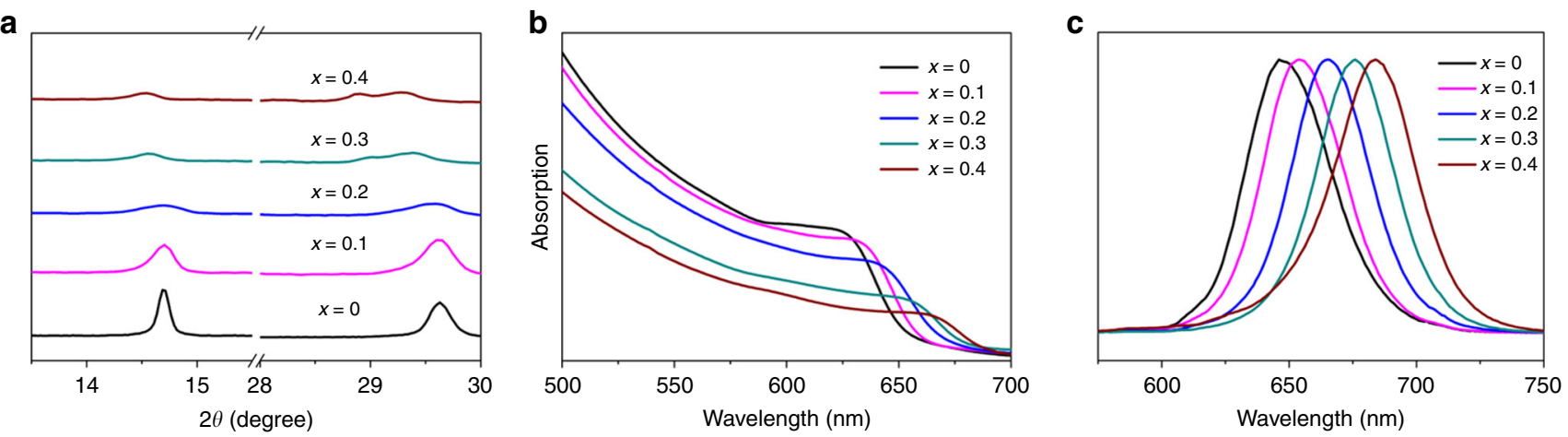

Fig. 1 Materials characterization of $\left.\mathrm{CsPb}_{1-x} \mathrm{Ba}_{x}\right|_{2} \mathrm{Br}$ with $x$ varies from 0 to 0.4 compositions. a XRD patterns, $\mathbf{b} U \mathrm{U}$-vis absorption, and $\mathbf{c} \mathrm{PL}$ emission spectra 
please refer to Supplementary Fig. 3). The thickness of the perovskite layer is estimated to be around $170 \mathrm{~nm}$. The photovoltaic parameters for $x=0,0.1,0.2,0.3$, and 0.4 are reported in Table 1 and the $J-V$ curves are plotted in Fig. 2a. The champion PSC fabricated using $\mathrm{CsPbI}_{2} \mathrm{Br}$ (without barium) exhibits a $V_{\mathrm{OC}}$ of $1.12 \mathrm{~V}$, a short circuit current $\left(J_{\mathrm{SC}}\right)$ of $13.4 \mathrm{~mA} \mathrm{~cm}^{-2}$, a fill factor of $73.8 \%$, yielding a PCE of $11.1 \%$, which is comparable to those previously reported in the literature ${ }^{20}$. As the barium fraction increases to $x \geq 0.1$, the $V_{\mathrm{OC}}$ enhanced dramatically from $1.12 \mathrm{~V}$ to around $1.27 \mathrm{~V}$, which accounts for roughly $15 \%$ of the total improvement. The highest obtained $V_{\mathrm{OC}}$ from one of the bestperforming devices fabricated using the $\mathrm{CsPb}_{0.8} \mathrm{Ba}_{0.2} \mathrm{I}_{2} \mathrm{Br}$ composition exhibited a value of $1.33 \mathrm{~V}$ (Supplementary Fig. 4). To the best of our knowledge, this is the highest reported $V_{\mathrm{OC}}$ for all-inorganic PSCs with a band gap lower than $2 \mathrm{eV}$. $J_{\mathrm{SC}}$ also shows a moderate increase as the barium concentration increases until $x=0.2$, benefiting from the red-shifted absorption, in line with the UV-vis characterization. Further increase of the barium concentration to $x=0.3$ leads to a dramatic decrease of $J_{\mathrm{SC}}$. The best PCE of $14.0 \%$ under one sun illumination was obtained for $x=0.2$. The stabilized power output at maximum power point (MPP) tracking of the best device shows a value of $13.6 \%$ along with a steady-state current of $13.8 \mathrm{~mA} \mathrm{~cm}^{-2}$ (Fig. 2b). The incident photo-to-current conversion efficiency (IPCE; Fig. 2c) measurement demonstrates a broad absorption range from 640 to $380 \mathrm{~nm}$ with the absorption onset at $680 \mathrm{~nm}$. The integrated $J_{\mathrm{SC}}$ of $14.1 \mathrm{~mA} \mathrm{~cm}^{-2}$ agrees also with the measured value.

To elucidate the substantial enhancement of $V_{\mathrm{OC}}$ upon the addition of barium, we investigated the charge recombination behavior within the bulk perovskite by time-resolved PL (Fig. 3a). The plots show increased PL lifetimes upon barium addition. This result suggests suppression of non-radiative recombination pathways, consistent with the improved $V_{\mathrm{OC}}$ measured in barium-containing PSCs. In addition, the X-ray photoelectron spectra (XPS; Fig. 3b) of $\mathrm{Pb} 4 f$ from $\mathrm{CsPbI}_{2} \mathrm{Br}$ show two small peaks at $136.9 \mathrm{eV}$ and $141.7 \mathrm{eV}$, which are ascribed to the

Table 1 Photovoltaic parameters of $\mathrm{CsPb}_{1-x} \mathrm{Ba}_{x} \mathrm{I}_{2} \mathrm{Br}$ (x=0 to 0.4) based inorganic PSCs

\begin{tabular}{|c|c|c|c|c|}
\hline $\begin{array}{l}\text { Barium molar } \\
\text { fraction, } x\end{array}$ & $V_{\text {oc }}(V)$ & $J_{S C}\left(m A c m^{-2}\right)$ & FF (\%) & PCE (\%) \\
\hline 0 & 1.12 & 13.4 & 73.8 & 11.1 \\
\hline 0.1 & 1.27 & 13.9 & 75.3 & 13.3 \\
\hline 0.2 & 1.28 & 14.0 & 78.2 & 14.0 \\
\hline 0.3 & 1.29 & 12.8 & 70.8 & 11.7 \\
\hline 0.4 & 1.27 & 10.1 & 66.1 & 8.4 \\
\hline
\end{tabular}

existence of metallic $\mathrm{Pb}$. These two peaks completely disappear at $20 \%$ barium addition, implying that the introduction of barium can effectively suppress the formation of metallic $\mathrm{Pb}$, which acts as non-radiative recombination centers and degrades PSCs performance. Thus, elimination of metallic $\mathrm{Pb}$ by barium can suppress the deep-level defects in $\mathrm{PSCs}^{26}$.

This spectacular improvement in $V_{\mathrm{OC}}$ was further elucidated using electroluminescence (EL) by studying the device with the champion $V_{\text {OC }}$ shown in Supplementary Fig. 4. We can indeed observe an increase of the external EL quantum efficiency by three orders of magnitude when comparing the $\mathrm{CsPb}_{0.8} \mathrm{Ba}_{0.2} \mathrm{I}_{2} \mathrm{Br}$ with a device without barium (Fig. 3c). It reaches $10^{-4}$ for currents similar to $J_{\mathrm{SC}}$, which corresponds to a non-radiative loss of $240 \mathrm{mV}^{27}$. Considering the theoretical maximum $V_{\mathrm{OC}}$ of $1.56 \mathrm{~V}$ for a solar cell based on a material with a band gap of 1.86 $\mathrm{eV}$, we calculate a $V_{\mathrm{OC}}$ of $1.32 \mathrm{~V}$, which is consistent with the experimental data ${ }^{27}$. Figure $3 \mathrm{c}$ shows that with the increase of the EL, the slope decreases, indicative of a reduced ideality factor, which approaches 2 for the barium-containing device ${ }^{28}$. These results indicate that the addition of barium into the $\mathrm{CsPb}_{2} \mathrm{Br}$ precursor solution significantly reduces non-radiative recombination, which leads to a much improved $V_{\text {OC. }}$.

Phase segregation analysis. We have recently shown that solidstate magic angle spinning (MAS) NMR is a suitable probe of the atomic-level microstructure in multi-component lead halide perovskites ${ }^{29-31}$. In particular, ${ }^{133} \mathrm{Cs}$ can be used to probe cesium-containing phases in organic-inorganic and all-inorganic halide perovskites ${ }^{30,32}$. To evidence whether or not barium is incorporated substitutionally into the material described here, we carried out ${ }^{133} \mathrm{Cs}$ MAS NMR measurements on bariumcontaining $\mathrm{CsPbBr}_{3}$ as a model compound (Fig. 4a). We chose the single-halide three-dimensional (3D) perovskite, as simultaneous introduction of bromides and iodides causes halide disorder leading to very broad ${ }^{133} \mathrm{Cs}$ resonances (Supplementary Fig. 5) ${ }^{32}$. The reference mechanochemical $\mathrm{CsPbBr}_{3}$ material shows a nearly pure perovskite phase (100.5 p.p.m.; Fig. 4a (I)). It contains $4 \%$ of a secondary impurity phase (226.6 p.p.m.). The material with $20 \mathrm{~mol} \%$ barium contains a perovskite phase $(85 \%)$, whose spectrum is indistinguishable from that of $\mathrm{CsPbBr}_{3}(100.5$ ppm) and impurity phases at 216.8 p.p.m. (14\%) and 336.5 p.p.m. (1\%). As the ${ }^{133} \mathrm{Cs}$ shift of the main perovskite phase is, to within error, unchanged, it strongly suggests that there is negligible barium substitution of lead in the $\mathrm{CsPBBr}_{3}$. This is expected from the substantially larger ionic radius of $\mathrm{Ba}^{2+}(135 \mathrm{pm})$ compared with $\mathrm{Pb}^{2+}(119 \mathrm{pm})$. For further confirmation we have carried out fully relativistic NMR shift calculations confirming that lead substitution by barium would lead to a ${ }^{133} \mathrm{Cs}$ shift with respect to $\mathrm{CsPbBr}$ of $c a+3$ p.p.m. for each closest barium cation on an Aor B-site (Supplementary Table 1), which would lead to a clear

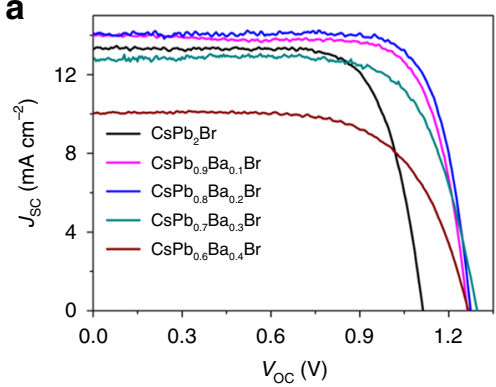

b

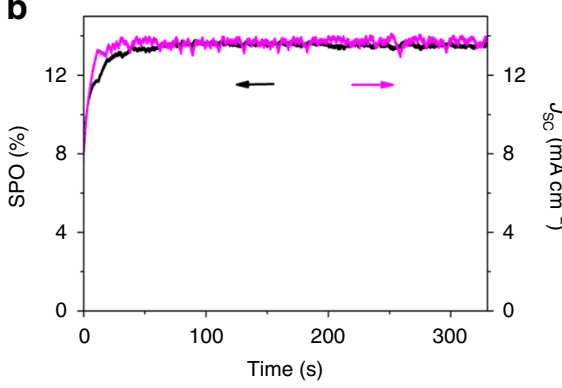

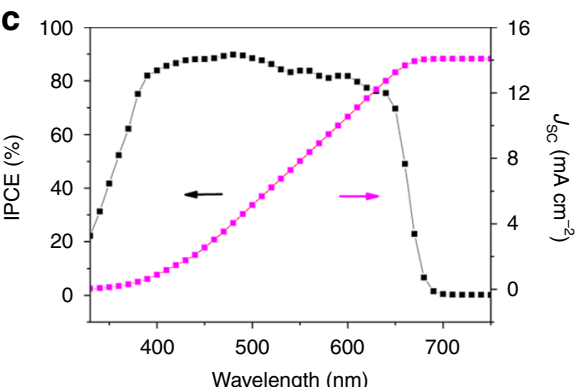

Fig. 2 Photovoltaic performance of PSCs. a $J-V$ performance of $\mathrm{CsPb}_{1-x} \mathrm{Ba}_{x} \mathrm{I}_{2} \mathrm{Br}$ ( $x=0$ to 0.4 ) based inorganic PSCs. b SPO and steady-state $J_{S C}$ of the $\mathrm{CsPb}_{0.8} \mathrm{Ba}_{0.2} \mathrm{I}_{2} \mathrm{Br}$-based PSCs. c IPCE and integrated $J_{\mathrm{SC}}$ of the $\mathrm{CsPb}_{0.8} \mathrm{Ba}_{0.2} \mathrm{I}_{2} \mathrm{Br}$-based PSCs 

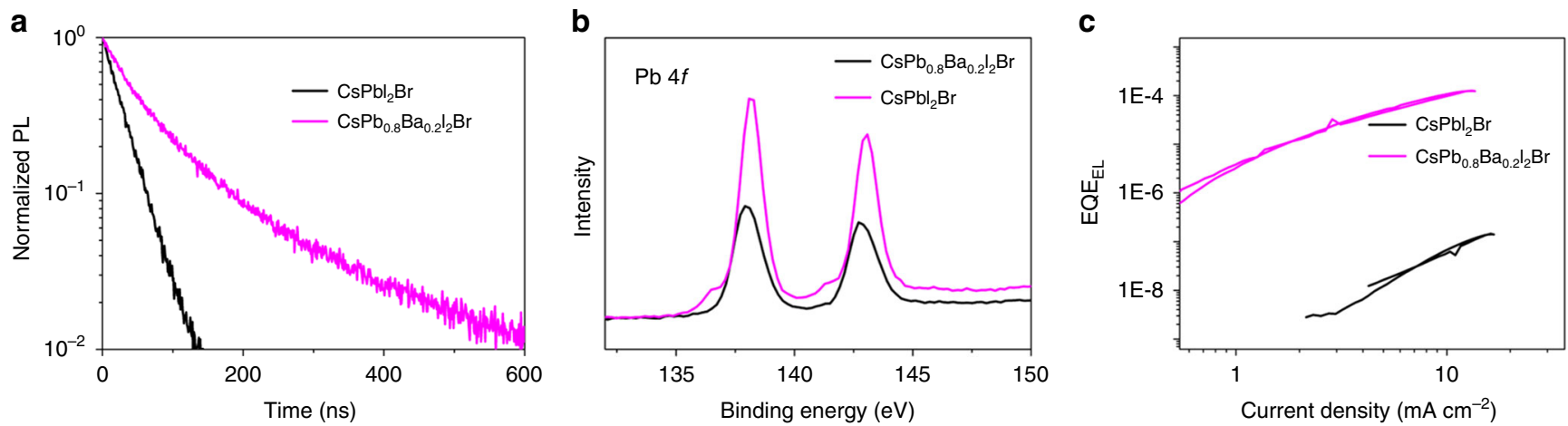

Fig. 3 Non-radiative recombination analysis. a TRPL spectra of $\mathrm{CsPb}_{2} \mathrm{Br}$ and $\mathrm{CsPb}_{0.8} \mathrm{Ba}_{0.2} \mathrm{I}_{2} \mathrm{Br}$ inorganic perovskite films. b Pb $4 f$ spectra from XPS surface analysis of $\mathrm{CsPb}_{2} \mathrm{Br}$ and $\mathrm{CsPb}_{0.8} \mathrm{Ba}_{0.2} \mathrm{I}_{2} \mathrm{Br}$ perovskite films. c EL measured during a J-V sweep from 0 to $1.6 \mathrm{~V}\left(1.4 \mathrm{~V}\right.$ for $\mathrm{CsPbl}{ }_{2} \mathrm{Br}$-based PSCs) and back with a rate of $10 \mathrm{mV} \mathrm{s}^{-1}$

change in the spectra. There are a number of known nonperovskite cesium lead bromides and cesium barium bromides with different stoichiometries. We have mechanochemically prepared $1: 2$ and 4:1 $\mathrm{CsBr}: \mathrm{PbBr}_{2}$, and $2: 1$ and $1: 2 \mathrm{CsBr}: \mathrm{BaBr}_{2}$ materials (Fig. 4a (III), (IV), (VI), (VII)). The 1:2 ratio of CsBr: $\mathrm{PbBr}_{2}$ yielded a mixture of $\mathrm{CsPb}_{2} \mathrm{Br}_{5}(224.6 \mathrm{ppm}, 83 \%)$ and $\mathrm{CsPbBr}_{3}$ (100.5 p.p.m., 17\%). The 4:1 ratio of $\mathrm{CsBr}: \mathrm{PbBr}_{2}$ yielded a mixture of unreacted $\mathrm{CsBr}$ (57\%, 249.6 p.p.m.), $\mathrm{CsPbBr}_{3}$ (17\%, 100.5 p.p.m.), and two other phases, which we did not attempt to identify (216.8 p.p.m., 19\% and 335.9 p.p.m., 6\%). The two latter non-perovskite correspond perfectly to the impurity phases identified in the $\mathrm{CsPb}_{0.8} \mathrm{Ba}_{0.2} \mathrm{Br}_{3}$ composition (Fig. 4a (II)). Both $\mathrm{CsBr}: \mathrm{BaBr}_{2}$ mixtures yielded a small amount of a new cesium barium bromide (227.0 p.p.m., $28 \%$ and $8 \%$ for the $1: 2$ and $2: 1$ ratios, respectively) and a corresponding amount of unreacted $\mathrm{CsBr}$ (Fig. 4a (V-VII)). The barium-based non-perovskite phase is present in the $\mathrm{CsPb}_{0.8} \mathrm{Ba}_{0.2} \mathrm{Br}_{3}$ composition (Fig. 4a (II), inset), albeit at a very low concentration (around 1\%). Taken together, the ${ }^{133} \mathrm{Cs}$ spectra show that there is no incorporation of barium into the model $\mathrm{CsPbBr}$.

Barium incorporation could also conceivably be probed using barium-137 NMR. Substitutional doping of barium on the A- or B-site should lead to a very symmetric (cubic or nearly cubic) ligand environment of barium and as a consequence to small electric-field gradient (EFG) tensors of the ${ }^{137} \mathrm{Ba}$ nucleus and thus relatively narrow ${ }^{137} \mathrm{Ba}$ NMR signals, as is the case for $\mathrm{BaTiO}_{3}{ }^{33}$. We have carried out fully relativistic EFG calculations for ${ }^{137} \mathrm{Ba}$ incorporated on an $\mathrm{A}$ - and $\mathrm{B}$-site of $\mathrm{CsPbBr}_{3}$ and confirmed that it should lead to a full width at half maximum (fwhm) of about 15 p.p.m. $(1.5 \mathrm{kHz})$. We were unable to detect any ${ }^{137} \mathrm{Ba}$ signal on the $\mathrm{CsPb}_{0.8} \mathrm{Ba}_{0.2} \mathrm{Br}_{3}$ composition over $12 \mathrm{~h}$ using an $\mathrm{RF}$ strength of $125 \mathrm{kHz}$, which should be sufficient to detect such a narrow resonance (Supplementary Fig. 6), suggesting that the barium species present in the composition have very large EFGs, consistent with asymmetric non-perovskite barium environments ${ }^{34}$. Taken together, the ${ }^{133} \mathrm{Cs}$ and ${ }^{137} \mathrm{Ba}$ NMR results are compelling evidence for no barium incorporation into the $\mathrm{Cs} \mathrm{PbBr}_{3}$ perovskite lattice. We expect them to carry over to the $\mathrm{CsPbI}_{2} \mathrm{Br}$ composition, as the chemical propensity of a cation to participate in substitutional doping has been shown to be halideindependent ${ }^{29,35}$. Thus, we conclude that the changes in band gap observed using optical spectroscopies are entirely due to the changes in the $\mathrm{I} / \mathrm{Br}$ ratio in the final perovskite composition rather than barium incorporation.

To quantify the effect of barium addition on the band gap, we plot the band gaps as a function of barium concentration $x$ in $\mathrm{CsPb}_{1-x} \mathrm{Ba}_{x} \mathrm{I}_{2} \mathrm{Br}$. The band gaps are estimated from the wavelength of the maxima in the PL spectra in Fig. 1c. We observe a linear dependence between the band gaps and barium concentration $x$ (Fig. 4b), which is described in Eq. (1):

$$
E_{\mathrm{g}}=1.92-0.27 x
$$

As the photoactive phase in the barium-containing material is still a cesium lead iodide-bromide, we prepared a series of $\mathrm{CsPb}$ $\left(\mathrm{I}_{y} \mathrm{Br}_{1-y}\right)_{3}(y=0-1)$ films with different $\mathrm{Br} / \mathrm{I}$ ratio, recorded their PL peak wavelengths, and converted them to the corresponding band gaps. We plot these band gaps against the iodide fraction $y$ and again observe a linear relationship as shown in Eq. (2):

$$
E_{\mathrm{g}}=2.32-0.60 y
$$

The empirical equation relating the barium fraction $(x)$ in $\mathrm{CsPb}_{1-x} \mathrm{Ba}_{x} \mathrm{I}_{2} \mathrm{Br}$ and the iodide fraction $(y)$ in $\mathrm{CsPb}\left(\mathrm{I}_{y} \mathrm{Br}_{1-y}\right)_{3}$ therefore has Eq. (3):

$$
y=0.45 x+0.667
$$

From this equation, we find that the band gap of the composition formally corresponding to the formula $\mathrm{CsPb}_{0.8} \mathrm{Ba}_{0.2} \mathrm{I}_{2} \mathrm{Br}$ is identical to that of the $\mathrm{CsPbI}_{2.27} \mathrm{Br}_{0.73}$ perovskite. The XRD characteristic peaks of $\mathrm{CsPbI}_{2.27} \mathrm{Br}_{0.73}$ and $\mathrm{CsPb}_{0.8} \mathrm{Ba}_{0.2} \mathrm{I}_{2} \mathrm{Br}$ perovskites also both occur at $14.5^{\circ}$ and $29.7^{\circ}$ (Fig. 4c). To further clarify the advantage of barium addition on the photovoltaic performance of cesium lead halide PSCs, we prepared devices based on $\mathrm{CsPbI}_{2.27} \mathrm{Br}_{0.73}$ and $0.8 \mathrm{CsPbI}{ }_{2} \mathrm{Br}$ $0.2 \mathrm{CsI}$ (i.e., $\mathrm{CsPbI}_{2} \mathrm{Br}$ doped with $20 \mathrm{~mol} \% \mathrm{CsI}$ ) as references. Their efficiencies were $8.82 \%$ and $8.64 \%$, respectively. Both types of PSCs show significantly lower $J_{\mathrm{SC}}$ and $V_{\mathrm{OC}}$ compared with $\mathrm{CsPb}_{0.8} \mathrm{Ba}_{0.2} \mathrm{I}_{2} \mathrm{Br}$-based solar cells (Supplementary Fig. 7). Furthermore, the recorded $J-V$ performance of the devices based on $\mathrm{CsPbI}_{2} \mathrm{Br}+x \mathrm{BaI}_{2}(x=0,0.1,0.2)$ shows that the addition of $\mathrm{BaI}_{2}$ increases the $V_{\mathrm{OC}}$ and the PCE (Supplementary Table 2 and Supplementary Fig. 8), indicating that Ba plays an important role in the improvement of photoelectric property of the corresponding devices. Besides, we found that no PL shift was observed for $\mathrm{CsPb}_{3}$ or $\mathrm{CsPbBr}_{3}$ perovskites by barium addition (Supplementary Fig. 9a, b). Meanwhile, based on first-principles electronic structure calculations (Supplementary Figs. 10 and 11), we found that the band gaps of barium-doped perovskites $\mathrm{CsPb}_{1-x} \mathrm{Ba}_{x} \mathrm{I}_{2} \mathrm{Br}$ should increase, rather than decrease. This is expected from the much larger band gap of $\mathrm{CsBaI}_{2} \mathrm{Br}$ than that of $\mathrm{CsPbI}_{2} \mathrm{Br}$ and the type-I bands alignment between them. In addition, simulation of hypothetical alloys of $\mathrm{CsPb}_{1-x} \mathrm{Ba}_{x} \mathrm{I}_{2} \mathrm{Br}(x=0,0.1,0.2,0.3,0.4,1)$ gives positive formation energies with respect to decomposition into $\mathrm{CsPb}_{2} \mathrm{Br}$ and $\mathrm{CsBaI}_{2} \mathrm{Br}$ (see Methods section and Supplementary Fig. 12). This indicates solid-solution miscibility gap and phase-separation behavior at low and room temperatures, consistent with the inability of $\mathrm{Ba}$ doped into perovskite lattice 
a
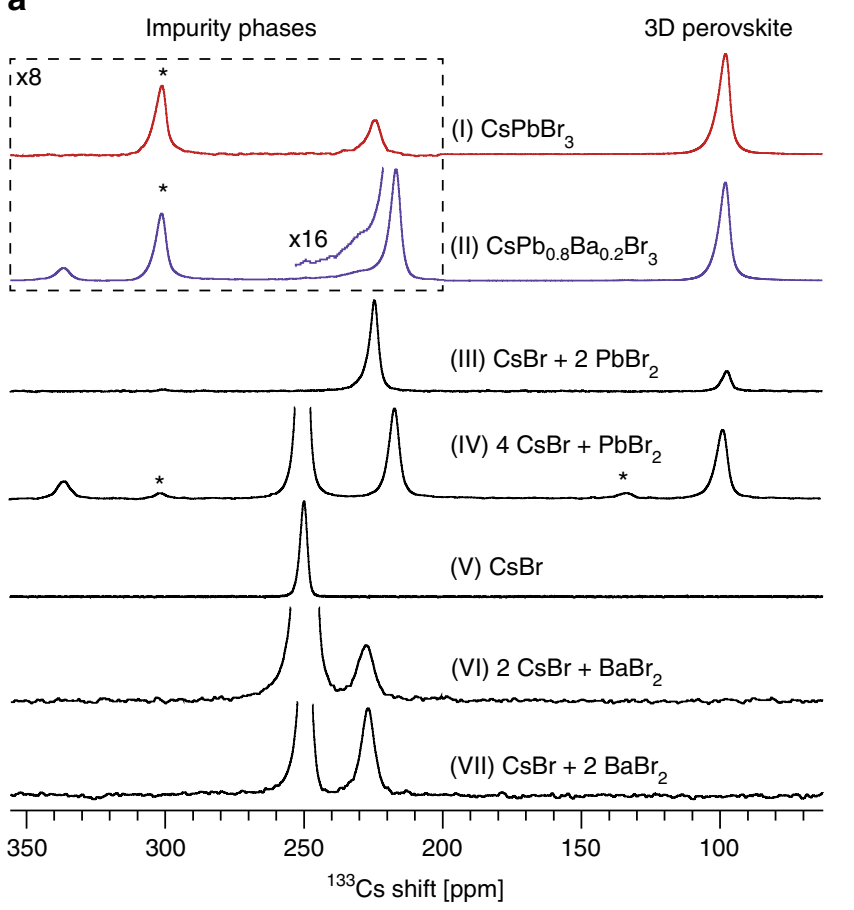

b

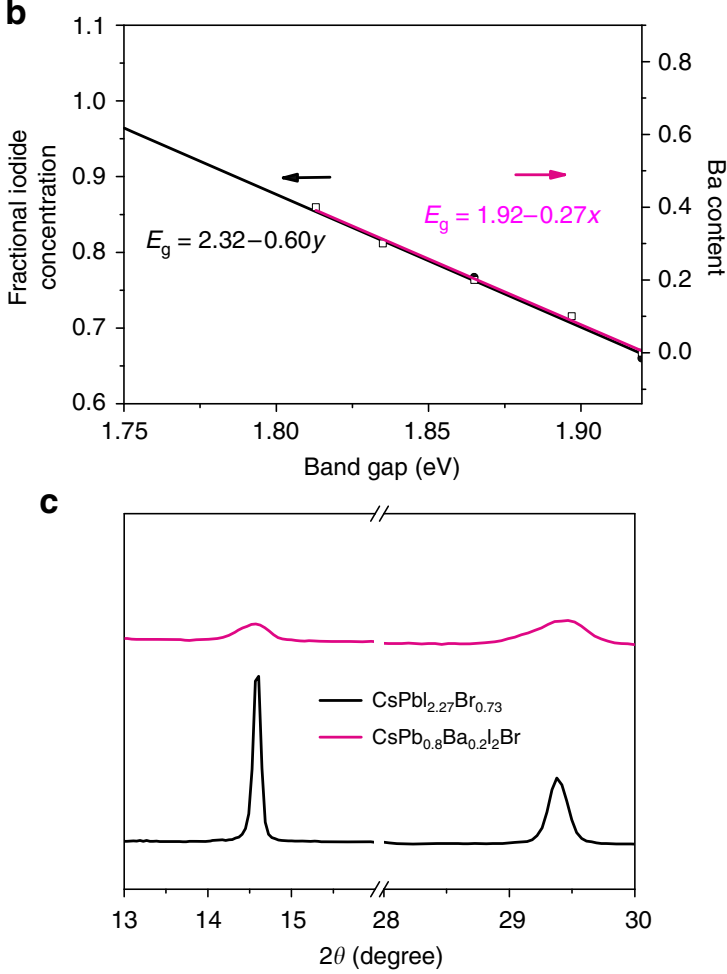

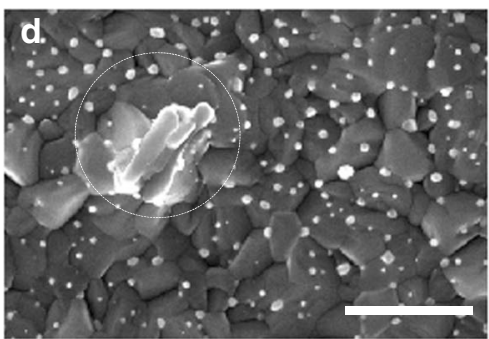
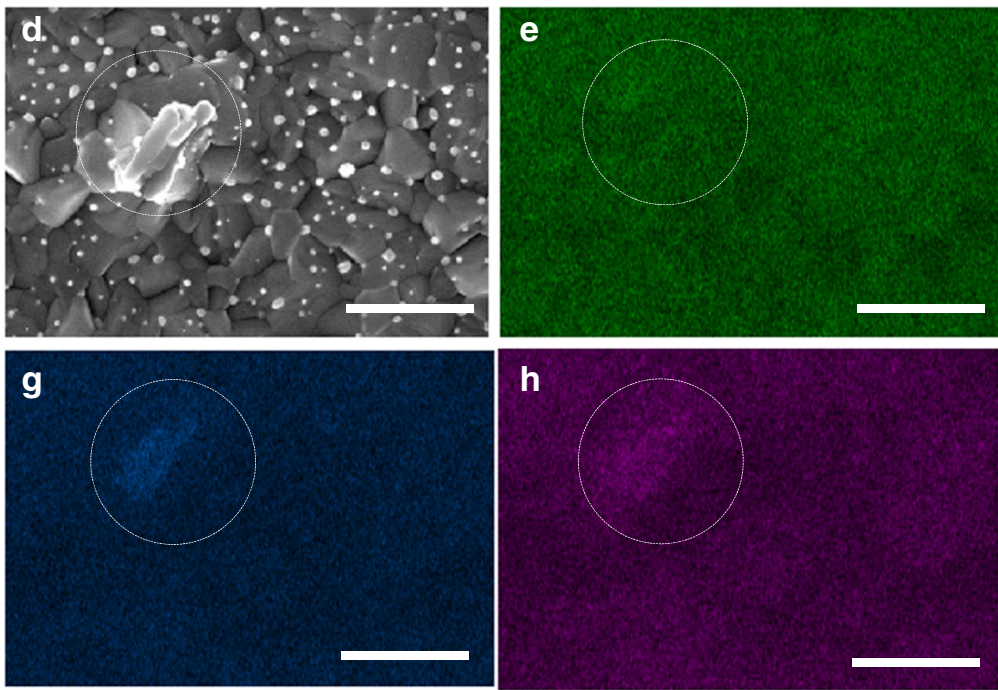

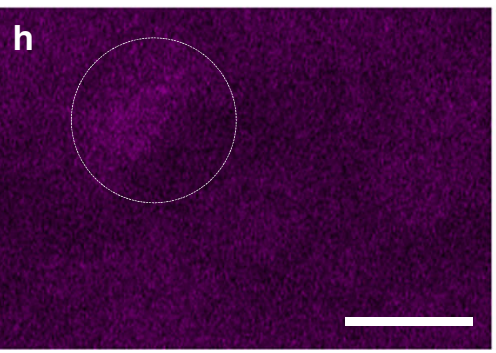

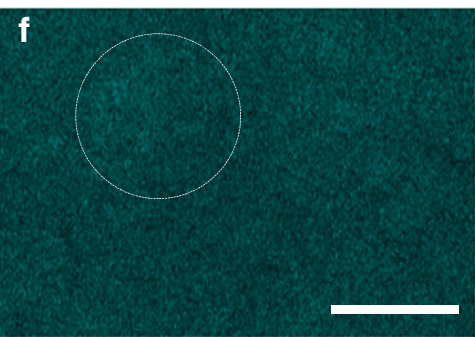

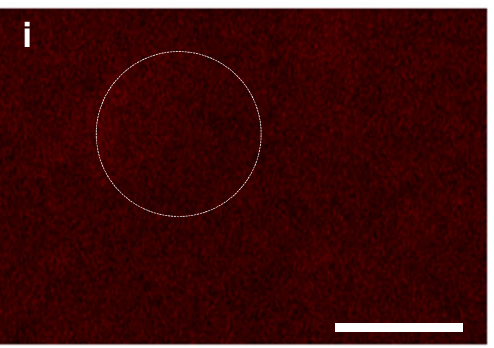

Fig. 4 Phase segregation analysis. a ${ }^{133} \mathrm{Cs}$ echo-detected solid-state MAS NMR spectra at $21.1 \mathrm{~T}, 298 \mathrm{~K}$, and $24 \mathrm{kHz}$ MAS of bulk mechanochemical compositions (I) $\mathrm{CsPbBr}_{3}$, (II) $\mathrm{CsPb}_{0.8} \mathrm{Ba}_{0.2} \mathrm{Br}_{3}$ (note that the formula designates the formal stoichiometry and does not correspond to a pure-phase material), (III) $\mathrm{CsBr}+\mathrm{PbBr}_{2}$ (1:2), (IV) $\mathrm{CsBr}+\mathrm{PbBr}_{2}$ (4:1), (V) neat $\mathrm{CsBr}$, (VI) $\mathrm{CsBr}+\mathrm{BaBr}_{2}$ (2:1), and ( $\left.\mathrm{VII}\right) \mathrm{CsBr}+\mathrm{BaBr}_{2}$ (1:2). Asterisks indicate spinning sidebands. The 200-350 p.p.m. range in $\mathbf{a}$ and $\mathbf{b}$ is magnified eight times to evidence the impurity phase. The inset in $\mathbf{b}$ shows a small amount of a bariumbased non-perovskite impurity phase. $\mathbf{b}$ The fractional iodide concentration and barium concentration vs. the experimental band gaps. The linear fits are included in the figure. $\mathbf{c}$ XRD patterns of $\mathrm{CsPb}_{2.27} \mathrm{Br}_{0.73}$ and $\mathrm{CsPb}_{0.8} \mathrm{Ba}_{0.2} \mathrm{I}_{2} \mathrm{Br}$ perovskite films. $\mathbf{d}$ an SEM image of a selected perovskite film area, the scale bar is $200 \mathrm{~nm}$. Elemental distributions of $\mathrm{CsPb}_{0.8} \mathrm{Ba}_{0.2} \mathrm{I}_{2} \mathrm{Br}$ inorganic perovskite film by EDS elemental mapping are shown as: e distribution of $\mathrm{Pb}$, $\mathbf{f}$ distribution of $\mathrm{I}, \mathbf{g}$ distribution of $\mathrm{Ba}$, $\mathbf{h}$ distribution of $\mathrm{Br}$, and $\mathbf{i}$ distribution of $\mathrm{Cs}$. The scale bars are $500 \mathrm{~nm}$

demonstrated experimentally. According to the Hume-Rothery rules $^{36}$, the formation of solid solution needs similar atomic radii, same crystal structures, same electronegativities, and same valence states of constituted components. Except for the crystal structure and valence state, the substantial mismatches in the other two factors between $\mathrm{Pb}$ and $\mathrm{Ba}$ (ionic radii: 1.19 and $1.35 \AA$ for $\mathrm{Pb}^{2+}$ and $\mathrm{Ba}^{2+}$, respectively; electronegativities) are responsible for the phase-separation behavior. Taken together, the results show that the shift of the XRD peak to higher angles in
Fig. 1a and the red shifts of PL and UV-Vis spectra in Fig. 1b, c are entirely due to the change of the $\mathrm{I} / \mathrm{Br}$ ratio in the perovskite, resulting from barium-induced anion exchange.

In order to map the distribution of the segregated phases in the perovskite films, we conducted Energy-dispersive spectroscopy (EDS)-based elemental mapping (Fig. 4e-i and Supplementary Fig. 13). The $\mathrm{CsPb}_{0.8} \mathrm{Ba}_{0.2} \mathrm{I}_{2} \mathrm{Br}$ perovskite film characterized by SEM (Fig. 4d) shows a uniform coverage of the perovskite on the substrate and an average crystal size of about $200 \mathrm{~nm}$. The surface 
is covered with a large number of bright spots (in the white circle). EDS mapping shows that these bright parts contain higher ratio of $\mathrm{Ba}$ and $\mathrm{Br}$ than the rest, whereas the dark areas possess more $\mathrm{I}$ and $\mathrm{Pb}$, which is verified by the EDS quantification (Supplementary Table 3). These results are consistent with the phenomenon of phase segregation evidenced by solid-state NMR. Thus, the formal $\mathrm{CsPb}_{1-x} \mathrm{Ba}_{x} \mathrm{I}_{2} \mathrm{Br}$ stoichiometry does not represent a pure-phase material but a mixture of perovskite and barium-rich non-perovskite phases. The depth profile XPS analysis shows that $\mathrm{Ba}$ is located not only on the surface but also inside the whole $\mathrm{CsPb}_{0.8} \mathrm{Ba}_{0.2} \mathrm{I}_{2} \mathrm{Br}$ film (Supplementary Fig. 14). As $\mathrm{Ba}$ is well distributed across the perovskite layer and cannot be incorporated into the perovskite crystal lattice, its location is most likely at the surface and grain boundaries ${ }^{37}$.

Perovskite film morphology and device stability. We also analyze the top-view film morphology by SEM after introducing barium during fabrication of $\mathrm{CsPb}_{2} \mathrm{Br}$ on a mesoporous $\mathrm{TiO}_{2}$ substrate (Supplementary Fig. 15). A pinhole-free and dense pristine $\mathrm{CsPbI}_{2} \mathrm{Br}$ film was obtained by carefully controlling the deposition conditions, as described in the experimental section. Upon addition of $10 \%$ barium, the perovskite grains become well resolved and the grain boundaries become clear. However, bare $\mathrm{TiO}_{2}$ surface is visible underneath, evidencing incomplete coverage of the substrate. For a barium molar fraction $x$ of 0.2 , we observe full coverage of the substrate with closely packed grains and numerous dots on the film surface. Further increase in the barium content generates pinholes and makes the grain profile blurry, leading to less dense films. Apparently, morphology reconstruction takes place when barium is added into the composition, with $x=0.2$ leading to optimal morphology for obtaining high performance solar cells.

To evaluate the stability of the complete devices, one of the best performing and unencapsulated $\mathrm{CsPb}_{0.8} \mathrm{Ba}_{0.2} \mathrm{I}_{2} \mathrm{Br}$-based inorganic PSCs was illuminated under continuous $100 \mathrm{~mW} \mathrm{~cm}^{-2}$ white light-emitting diode (LED) irradiation in an $\mathrm{N}_{2}$ atmosphere with MPP tracking. The control $\mathrm{CsPbI}_{2} \mathrm{Br}$-based PSC was monitored under identical conditions (Supplementary Fig. 16). The $\mathrm{CsPb}_{0.8} \mathrm{Ba}_{0.2} \mathrm{I}_{2} \mathrm{Br}$-based device showed a slow decrease of PCE over time, maintaining $\sim 80 \%$ of the initial efficiency after $450 \mathrm{~h}$. During the same testing period, the PCE of $\mathrm{CsPbI}_{2} \mathrm{Br}$-based PSC dropped dramatically to $40 \%$ of the initial value within $90 \mathrm{~h}$ and eventually $<20 \%$ after $350 \mathrm{~h}$ of illumination. These results indicate that the $\mathrm{CsPb}_{0.8} \mathrm{Ba}_{0.2} \mathrm{I}_{2} \mathrm{Br}$-based PSCs demonstrate better stability than $\mathrm{CsPbI}_{2} \mathrm{Br}$-based devices. As iodide-rich all-inorganic perovskites are known to be rather sensitive to moisture, we conclude that the enhanced stability of $\mathrm{CsPb}_{0.8} \mathrm{Ba}_{0.2} \mathrm{I}_{2} \mathrm{Br}$-based PSCs is probably due to protection of the film surface with the barium-rich phases or defects reduction within the device ${ }^{38}$.

\section{Discussion}

In conclusion, we report a function of adding barium to the allinorganic $\mathrm{CsPbI}_{2} \mathrm{Br}$ perovskite and its use as an absorber layer in inorganic PSCs that achieves a PCE of $14.0 \%$ under one sun illumination. By applying solid-state NMR, we have shown that barium does not incorporate into the perovskite lattice. Rather, it segregates into barium-based non-perovskite phases. This in turn leads to a change in the iodide-to-bromide ratio in the photoactive perovskite layer. This atomic-level insight provides a full explanation of the changes observed in the optical spectra and $\mathrm{XRD}$ patterns. EL measurements indicate that the non-radiative recombination is effectively inhibited upon the addition of barium, yielding a much higher $V_{\mathrm{OC}}$ of $1.33 \mathrm{~V}$ and a high EL EQE value. The addition of barium also improves the quality of perovskite films and leads to an increase in PCE. Our study highlights that phase segregation is a critical design criterion, which should be taken into account and investigated for other additives.

\section{Methods}

Preparation of perovskite solutions. CsI (259.8 mg), $183.5 \mathrm{mg} \mathrm{PbBr}_{2}$, and 230.5 $\mathrm{mg} \mathrm{PbI}{ }_{2}$ were mixed with $1 \mathrm{ml}$ anhydrous DMSO with continuous heating at $80^{\circ} \mathrm{C}$ for $6 \mathrm{~h}$ until a completely clear $\mathrm{CsPbI}_{2} \mathrm{Br}$ solution was formed. $\mathrm{BaI}_{2}(391.2 \mathrm{mg})$ and $212.8 \mathrm{mg} \mathrm{CsBr}$ were dissolved into a mixture of $1.4 \mathrm{ml} \mathrm{DMSO}$ and formiamide ( $\mathrm{v}: \mathrm{v}=1: 1)$ to form a clear $\mathrm{CsBaI}_{2} \mathrm{Br}$ solution. The $\mathrm{CsPb}_{1-x} \mathrm{Ba}_{x} \mathrm{I}_{2} \mathrm{Br}(x=0-1)$ perovskite solutions were prepared by mixing the above two solutions with appropriate ratio in a nitrogen-filled glovebox and alloyed overnight. The $1 \mathrm{M}$ solutions of $\mathrm{CsPbI}_{2.27} \mathrm{Br}_{0.73}, 0.8 \mathrm{CsPbI}_{2} \mathrm{Br}-0.2 \mathrm{CsI}$, and $\mathrm{CsPbI}_{2} \mathrm{Br}+x \mathrm{BaI}_{2}(x=0.1,0.2)$ were also prepared stoichiometrically.

Device fabrication. The perovskite device was fabricated with the following procedure. The FTO conducting glass (Nippon Corp., Japan) with the square resistance of $10 \Omega \mathrm{sq}^{-1}$ was cleaned with $2 \%$ Hellmanex solution, acetone, and ethanol by sonication for 15,10 , and $10 \mathrm{~min}$, separately. The $40 \mathrm{~nm}$-thick $\mathrm{TiO}_{2}$ compact layer was deposited on top of cleaned FTO glass by spray pyrolysis at $450{ }^{\circ} \mathrm{C}$ from a precursor solution containing $0.6 \mathrm{ml}$ titanium diisopropoxide bis(acetylacetonate) and $0.4 \mathrm{ml}$ acetoacetate in $9 \mathrm{ml}$ anhydrous ethanol. The $150 \mathrm{~nm}$-thick mesoporous $\mathrm{TiO}_{2}$ layer was then deposited by spin-coating a diluted $\mathrm{TiO}_{2}$ paste $(30 \mathrm{~nm}$ particle size, Dyesol) in absolute ethanol at the speed of 5000 r.p.m. for 10 s. These $\mathrm{TiO}_{2}$ films were dried at $80^{\circ} \mathrm{C}$ for $5 \mathrm{~min}$ and further sintering process at $450{ }^{\circ} \mathrm{C}$ for $1 \mathrm{~h}$ under continuous dry air flow. After cooling down to $\sim 100^{\circ} \mathrm{C}$, these films were immediately transferred into glovebox filled with dry air. The $\mathrm{CsPb}_{1-x} \mathrm{Ba}_{x} \mathrm{I}_{2} \mathrm{Br}(x=$ 0 to 1) perovskite films were prepared by spin-coating the aforementioned precursor solutions in a two steps program at 1000 r.p.m. and 3000 r.p.m. for $10 \mathrm{~s}$ and $30 \mathrm{~s}$, respectively. The films were then left for $5 \mathrm{~min}$ before being annealed at $280^{\circ} \mathrm{C}$ for $10 \mathrm{~min}$. After cooling down to room temperature, the spiro-OMeTAD (Merck) chlorobenzene solution $\left(90 \mathrm{mg} \mathrm{ml}^{-1}\right)$ with $20.6 \mu \mathrm{l}$ bis(trifluromethylsulfonyl)imide lithium salt (LiTFSI, Sigma-Aldrich, $520 \mathrm{mg} \mathrm{ml}^{-1}$ in acetonitrile) and $35.5 \mu \mathrm{l} \mathrm{4}$ tert-butylpyridine (t-BP, Sigma-Aldrich) was spun on top of the perovskite film at 4000 r.p.m. for 20 s. An $80 \mathrm{~nm}$-thick Au back-contact metal electrode was finally thermal-evaporated to complete the device construction.

X-ray diffraction. The perovskite films on mesoporous $\mathrm{TiO}_{2}$ substrates were prepared exactly as described in the device fabrication section. XRD patterns were acquired with a PANalytical Empyrean diffractometer in the transmissionreflection mode, using the $\mathrm{Cu} \mathrm{Ka}$ radiation and the $\mathrm{Ni} \beta$-filter.

Scanning electron microscope. The perovskite films were deposited on mesoporous $\mathrm{TiO}_{2}$ substrates to exactly reflect the true film morphology. A highresolution SEM (Zeiss Merlin) with in-lens detector was used for morphology characterization. EDS was carried out in SEM mode.

Optical characterization. UV-vis measurements were performed on a Varian Cary 5. PL spectra were obtained with Fluorolog 322 (Horiba Jobin Yvon, Ltd) with the range of wavelength from 500 to $800 \mathrm{~nm}$ by exciting at $450 \mathrm{~nm}$ with a standard 450 -W Xenon CW lamp. The samples were mounted at $60^{\circ}$ and the emission recorded at $90^{\circ}$ from the incident beam path. Time-resolved PL was performed using Fluorolog 322 spectrofluorometer (Horiba Jobin Yvon, Ltd). A NanoLED405L (Horiba) laser diode $(405 \mathrm{~nm})$ was used for excitation. The samples were mounted at $60^{\circ}$ and the emission collected at $90^{\circ}$ from the incident beam path. The detection monochromator was set to $650 \mathrm{~nm}$ and the PL was recorded using a picosecond photodetection module (TBX-04, Horiba Scientific).

Perovskite mechanosynthesis. Starting materials were stored inside a glovebox under argon. Perovskite powders were synthesized by grinding the reactants in an electric ball mill (Retsch Ball Mill MM-200 using a grinding jar $(10 \mathrm{ml})$ and a ball $(\varnothing 10 \mathrm{~mm})$ for $30 \mathrm{~min}$ at $25 \mathrm{~Hz}$. The resulting powders were annealed at $280{ }^{\circ} \mathrm{C}$ for $10 \mathrm{~min}$ to reproduce the thin-film synthetic procedure. The amounts of reagents taken into the synthesis were as follows:

$\mathrm{CsPb}_{0.8} \mathrm{Ba}_{0.2} \mathrm{Br}_{3}: 0.213 \mathrm{~g} \mathrm{CsBr}(1.00 \mathrm{mmol}), 0.059 \mathrm{~g} \mathrm{BaBr}_{2}(0.20 \mathrm{mmol})$, and $0.294 \mathrm{~g} \mathrm{PbBr}_{2}(0.80 \mathrm{mmol})$.

$\mathrm{CsPbBr}_{3}: 0.213 \mathrm{~g} \mathrm{CsBr}(1.00 \mathrm{mmol})$ and $0.367 \mathrm{~g} \mathrm{PbBr}_{2}(1.00 \mathrm{mmol})$.

$\mathrm{CsBr}+2 \mathrm{PbBr}_{2}: 0.107 \mathrm{~g} \mathrm{CsBr}(0.50 \mathrm{mmol})$ and $0.367 \mathrm{~g} \mathrm{PbBr}_{2}(1.00 \mathrm{mmol})$.

$4 \mathrm{CsBr}+\mathrm{PbBr}_{2}: 0.213 \mathrm{~g} \mathrm{CsBr}(1.00 \mathrm{mmol})$ and $0.092 \mathrm{~g} \mathrm{PbBr}_{2}(0.25 \mathrm{mmol})$

$2 \mathrm{CsBr}+\mathrm{BaBr}_{2}: 0.213 \mathrm{~g} \mathrm{CsBr}(1.00 \mathrm{mmol})$ and $0.149 \mathrm{~g} \mathrm{BaBr}_{2}(0.5 \mathrm{mmol})$.

$1 \mathrm{CsBr}+2 \mathrm{BaBr}_{2}: 0.107 \mathrm{~g} \mathrm{CsBr}(0.50 \mathrm{mmol})$ and $0.297 \mathrm{~g} \mathrm{BaBr}_{2}(1 \mathrm{mmol})$.

Solid-state NMR measurements. Room temperature ${ }^{133} \mathrm{Cs}(181.1 \mathrm{MHz})$ and ${ }^{137} \mathrm{Ba}(100.0 \mathrm{MHz})$ NMR spectra were recorded on a Bruker Avance Neo 21.1T spectrometer equipped with a $3.2 \mathrm{~mm}$ CPMAS probe. ${ }^{133} \mathrm{Cs}$ shifts were referenced to $1 \mathrm{M}$ aqueous solution of $\mathrm{CsCl}$, using solid $\mathrm{CsI}(\delta=271.05$ p.p.m. $)$ as a secondary reference ${ }^{39} .{ }^{137} \mathrm{Ba}$ shift were referenced to solid $\mathrm{BaZrO}_{3}$ using $\mathrm{BaO}$ as a secondary 
reference (481 p.p.m.) ${ }^{33}$. Quantitative ${ }^{133} \mathrm{Cs}$ spectra were acquired using a recycle delay of $450 \mathrm{~s}$.

Electronic structure calculations of $\mathrm{Ba}$-doped $\mathrm{CsPb}_{2} \mathrm{Br}$ perovskites. Electronic band structure calculations of $\mathrm{Ba}$-doped $\mathrm{CsPbI}_{2} \mathrm{Br}$ perovskites were within the framework of density functional theory (DFT) by using plane-wave pseudopotential methods as implemented in the Vienna Ab initio Simulation Package ${ }^{40,41}$. The electron-ion interactions were described by the projected augmented wave pseudopotentials with the $6 s(\mathrm{Cs}), 5 s$, and $5 p(\mathrm{Br}), 5 s$ and $5 p(\mathrm{I})$, and $6 s$ and $6 p(\mathrm{~Pb})$ electrons treated as valence electrons. We used the generalized gradient approximation of Perdew-Burke-Ernzerhof (PBE) form ${ }^{42}$ as exchange-correlation functional. The kinetic energy cutoff for the plane-wave basis of $300 \mathrm{eV}$ was used and the $k$-point meshes of spacing were set to $2 \pi \times 0.04 \AA^{-1}$ for electronic Brillouin zone integration. The structures of $\mathrm{Ba}$-doped perovskites $\mathrm{CsPb}_{1-x} \mathrm{Ba}_{x} \mathrm{I}_{2} \mathrm{Br}(x=$ $0.03375,0.0625,0.125)$ were constructed through the $2 \times 2 \times 2,2 \times 1 \times 2,1 \times 1 \times$ 2 supercells of the $\mathrm{CsPbI}_{2} \mathrm{Br}$ unit cell, in which $\mathrm{Pb}$ atoms are randomly substituted by $\mathrm{Ba}$ atoms according to Ba concentration $x$. The structures are optimized through total energy minimization with the residual forces on the atoms converged to below $0.05 \mathrm{eV} / \AA$. The spin-orbit coupling was included in the electronic structure calculations. Although the DFT-PBE approach is known to underestimate the band gaps of semiconductors due to the self-interaction error issue, but in the current case it is reliable to predict the correct trend on the calculated band gaps of Badoped perovskites $\mathrm{CsPb}_{1-x} \mathrm{Ba}_{x} \mathrm{I}_{2} \mathrm{Br}$ changing with $\mathrm{Ba}$ concentration $x$.

The hypothetical alloys of $\mathrm{CsPb}_{1-x} \mathrm{Ba}_{x} \mathrm{I}_{2} \mathrm{Br}(x=0,0.1,0.2,0.3,0.4,1)$ were simulated through the special quasirandom structure ${ }^{43}$ to mimic random disorder within a 200 atom supercell. The alloy formation energy is defined as $\Delta H=E\left(\mathrm{CsPb}_{1-x} \mathrm{Ba}_{x} \mathrm{I}_{2} \mathrm{Br}\right)-x E\left(\mathrm{CsPb}_{2} \mathrm{Br}\right)-(1-x) E\left(\mathrm{CsBaI}_{2} \mathrm{Br}\right)$, where $E\left(\mathrm{CsPb}_{1-x} \mathrm{Ba}_{x} \mathrm{I}_{2} \mathrm{Br}\right), E\left(\mathrm{CsPbI}_{2} \mathrm{Br}\right)$, and $E\left(\mathrm{CsBaI}_{2} \mathrm{Br}\right)$ refer to the free energy of $\mathrm{CsPb}_{1-x} \mathrm{Ba}_{x} \mathrm{I}_{2} \mathrm{Br}, \mathrm{CsPb}_{2} \mathrm{Br}$, and $\mathrm{CsBaI}_{2} \mathrm{Br}$ phases, respectively. We assumed the $3 \mathrm{D}$ perovskite as the structure of $\mathrm{CsBaI}_{2} \mathrm{Br}$ to evaluate $\Delta H$. The resulted value is positive, indicating a phase-separation condition. If there was the ground-state structure with the even lower energy of $\mathrm{CsBaI}_{2} \mathrm{Br}$, we can expect that the $\Delta H$ would be even larger in the positive magnitude. Therefore, with the assumption of $\mathrm{CsBaI}_{2} \mathrm{Br}$ being 3D perovskite, our calculations give a reasonable evaluation of the phase-separation condition. The positive $\Delta H$ for all the $\mathrm{Ba}$ fractions indicates that there is no stable configuration for the alloyed perovskites at $0 \mathrm{~K}$ and phaseseparation will occur. This may be attributed to the substantial ionic radius and electronegativity mismatch between $\mathrm{Pb}$ and $\mathrm{Ba}$.

X-ray photoelectron spectroscopy. The perovskite films were deposited on plain glass substrates as described above. XPS measurements were carried out using a PHI VersaProbe II scanning XPS microprobe (Physical Instruments AG, Germany). Analysis was performed using a monochromatic Al Ka X-ray source of $24.8 \mathrm{~W}$ power with a beam size of $100 \mu \mathrm{m}$. The spherical capacitor analyzer was set at $45^{\circ}$ take-off angle with respect to the sample surface. The pass energy was 46.95 $\mathrm{eV}$ yielding a fwhm of $0.91 \mathrm{eV}$ for the $\mathrm{Ag} 3 d 5 / 2$ peak. Curve fitting was performed using the PHI Multipak software.

Photovoltaic performance. The PSCs were tested with a $450 \mathrm{~W}$ xenon light source (Oriel). The light intensity was calibrated by a silicon photodiode equipped with an IR-cutoff filter (KG3, Schott) and was recorded for each measurement. The current-voltage curves $(J-V$ curves) of the devices were recorded by applying an external voltage bias with Keithley 2400 to give the corresponding current response. A black metal mask with an area of $0.16 \mathrm{~cm}^{-2}$ was applied to define the active area of the cells and to avoid the overestimation of the light input.

IPCE measurements were carried from the monochromatic visible photons, from Gemini-180 double monochromator Jobin Yvon, Ltd (UK), powered by a $300 \mathrm{~W}$ xenon light source (ILC Technology, USA) superimposed on a $1 \mathrm{~mW} \mathrm{~cm}-2$ LED light. The monochromatic incident light was passed through a chopper running at $8 \mathrm{~Hz}$ frequency and the on/off ratio was measured by an operational amplifier.

Stability. Stability measurements were performed with a Biologic MPG2 potentiostat under a full AM 1.5 Sun-equivalent white LED lamp. The devices were masked to $0.16 \mathrm{~cm}^{2}$ and were connected to a separate channel of a potentiostat. A continuous flow of dry nitrogen gas was flushed into the custom-built airtight weathering chamber as the sample holder. The devices were measured in situ with a MPP tracking routine under continuous illumination. The MPP was updated every $10 \mathrm{~s}$ by a standard perturb-and-observe method. A Peltier element in direct contact with the films was used to control the temperature of the devices. A Pt100 thermometer inserted between the Peltier element and the film was used to measure the temperature of the devices. Every $30 \mathrm{~min}$ a $J-V$ curve was recorded, to track the evolution of individual $J-V$ parameters. The setup is centrally controlled through a LabView interface allowing for automatic programming of experiments (temperature, illumination, atmosphere, and electronic measurements).

Reporting summary. Further information on research design is available in the Nature Research Reporting Summary linked to this article.

\section{Data availability}

The data that support the plots within this paper and other findings of this study are available in separate Supplementary Source Data Files in Supplementary Information section. All other relevant data are available from the corresponding authors upon reasonable request.

Received: 3 April 2019; Accepted: 24 September 2019; Published online: 15 October 2019

\section{References}

1. Stoumpos, C. C., Malliakas, C. D. \& Kanatzidis, M. G. Semiconducting tin and lead iodide perovskites with organic cations: phase transitions, high mobilities, and near-infrared photoluminescent properties. Inorg. Chem. 52, 9019-9038 (2013).

2. Kojima, A., Teshima, K., Shirai, Y. \& Miyasaka, T. Organometal halide perovskites as visible-light sensitizers for photovoltaic cells. J. Am. Chem. Soc. 131, 6050-6051 (2009).

3. Kim, H. S. et al. Lead iodide perovskite sensitized all-solid-state submicron thin film mesoscopic solar cell with efficiency exceeding 9\%. Sci. Rep. 2, 591 (2012).

4. Lee, M. M., Teuscher, J., Miyasaka, T., Murakami, T. N. \& Snaith, H. J. Efficient hybrid solar cells based on meso-superstructured organometal halide perovskites. Science 338, 643-647 (2012).

5. Jeon, N. J. et al. Compositional engineering of perovskite materials for highperformance solar cells. Nature 517, 476-480 (2015).

6. Laboratory, N. R. E. Best Research-Cell Efficiencies https://www.nrel.gov/pv/ assets/pdfs/best-research-cell-efficiencies.20190703.pdf (2019).

7. Berhe, T. A. et al. Organometal halide perovskite solar cells: degradation and stability. Energy Environ. Sci. 9, 323-356 (2016).

8. Robert, F. Cesium fortifies next-generation solar cells. Science 351, 113-114 (2016).

9. Yang, S. et al. Functionalization of perovskite thin films with moisture-tolerant molecules. Nat. Energy 1, 15016 (2016).

10. Domanski, K., Alharbi, E. A., Hagfeldt, A., Grätzel, M. \& Tress, W. Systematic investigation of the impact of operation conditions on the degradation behaviour of perovskite solar cells. Nat. Energy 3, 61-67 (2018).

11. Liang, J., Liu, J. \& Jin, Z. All-inorganic halide perovskites for optoelectronics: progress and prospects. Sol. RRL 1, 1700086 (2017).

12. Swarnkar, A. et al. Quantum dot-induced phase stabilization of $a-\mathrm{CsPbI}_{3}$ perovskite for high-efficiency photovoltaics. Science 354, 92-95 (2016)

13. Sutton, R. J. et al. Bandgap-tunable cesium lead halide perovskites with high thermal stability for efficient solar cells. Adv. Energy Mater. 6, 1502458 (2016).

14. Polman, A., Knight, M., Garnett, E. C., Ehrler, B. \& Sinke, W. C. Photovoltaic materials: present efficiencies and future challenges. Science 352, 307 (2016).

15. Xiang, W. et al. Europium-doped $\mathrm{CsPbI}_{2} \mathrm{Br}$ for stable and highly efficient inorganic perovskite solar cells. Joule 3, 205-214 (2019).

16. Zhou, Y. \& Zhao, Y. Chemical stability and instability of inorganic halide perovskites. Energy Environ. Sci. 12, 1495-1511 (2019).

17. Ke, W. \& Kanatzidis, M. G. Prospects for low-toxicity lead-free perovskite solar cells. Nat. Commun. 10, 965 (2019).

18. Hao, F., Stoumpos, C. C., Cao, D. H., Chang, R. P. H. \& Kanatzidis, M. G. Lead-free solid-state organic-inorganic halide perovskite solar cells. Nat. Photonics 8, 489-494 (2014).

19. Ju, M. G., Dai, J., Ma, L. \& Zeng, X. C. Lead-free mixed tin and germanium perovskites for photovoltaic application. J. Am. Chem. Soc. 139, 8038-8043 (2017).

20. Shi, Z. et al. Lead-free organic-inorganic hybrid perovskites for photovoltaic applications: recent advances and perspectives. Adv. Mater. 29, 1605005 (2017).

21. Mir, W. J., Jagadeeswararao, M., Das, S. \& Nag, A. Colloidal Mn-doped cesium lead halide perovskite nanoplatelets. ACS Energy Lett. 2, 537-543 (2017).

22. Lau, C. F. J. et al. Strontium-doped low-temperature-processed $\mathrm{CsPbI}_{2} \mathrm{Br}$ perovskite solar cells. ACS Energy Lett. 2, 2319-2325 (2017).

23. Bai, $\mathrm{D}$. et al. Interstitial $\mathrm{Mn}^{2+}$-driven high-aspect-ratio grain growth for lowtrap-density microcrystalline films for record efficiency $\mathrm{CsPb}_{2} \mathrm{Br}$ solar cells. ACS Energy Lett. 3, 970-978 (2018).

24. Klug, M. T. et al. Tailoring metal halide perovskites through metal substitution: influence on photovoltaic and material properties. Energy Environ. Sci. 10, 236-246 (2017).

25. Kubicki, D. J. et al. Doping and phase segregation in $\mathrm{Mn}^{2+}$ - and $\mathrm{Co}^{2+}$-doped lead halide perovskites from ${ }^{133} \mathrm{Cs}$ and $1 \mathrm{H}$ NMR relaxation enhancement. $J$. Mater. Chem. A 7, 2326-2333 (2019).

26. Bi, D. Q. et al. Polymer-templated nucleation and crystal growth of perovskite films for solar cells with efficiency greater than 21\%. Nat. Energy 1, 5 (2016). 
27. Tress, W. et al. Predicting the open-circuit voltage of $\mathrm{CH}_{3} \mathrm{NH}_{3} \mathrm{PbI}_{3}$ perovskite solar cells using electroluminescence and photovoltaic quantum efficiency spectra: the role of radiative and non-radiative recombination. Adv. Energy Mater. 3, 6 (2015).

28. Tress, W. et al. Understanding the rate-dependent $J-V$ hysteresis, slow time component, and aging in $\mathrm{CH}_{3} \mathrm{NH}_{3} \mathrm{PbI}_{3}$ perovskite solar cells: the role of a compensated electric field. Energy Environ. Sci. 8, 995-1004 (2015).

29. Kubicki, D. J. et al. Cation dynamics in mixed-cation (MA $)_{x}(\mathrm{FA})_{1-x} \mathrm{PbI}_{3}$ hybrid perovskites from solid-state NMR. J. Am. Chem. Soc. 139, 10055-10061 (2017).

30. Kubicki, D. J. et al. Phase segregation in Cs-, Rb- and K-doped mixed-cation $(\mathrm{MA})_{x}(\mathrm{FA})_{1-x} \mathrm{PbI}_{3}$ hybrid perovskites from solid-state NMR. J. Am. Chem. Soc. 139, 14173-14180 (2017).

31. Kubicki, D. J. et al. Phase segregation in potassium-doped lead halide perovskites from ${ }^{39} \mathrm{~K}$ solid-state NMR at $21.1 \mathrm{~T}$. J. Am. Chem. Soc. 140, 7232-7238 (2018).

32. Prochowicz, D. et al. One-step mechanochemical incorporation of an insoluble cesium additive for high performance planar heterojunction solar cells. Nano Energy 49, 523-528 (2018).

33. Dec, S. F. et al. Solid-state multinuclear NMR-studies of ferroelectric, piezoelectric, piezoelectric, and related materials. Inorg. Chem. 32, 955-959 (1993).

34. Hamaed, H., Ye, E., Udachin, K. \& Schurko, R. W. Solid-state ${ }^{137}$ Ba NMR spectroscopy: an experimental and theoretical investigation of ${ }^{137} \mathrm{Ba}$ electric field gradient tensors and their relation to structure and symmetry. J. Phys. Chem. B 114, 6014-6022 (2010).

35. Kubicki, D. J. et al. Formation of stable mixed guanidiniummethylammonium phases with exceptionally long carrier lifetimes for highefficiency lead iodide-based perovskite photovoltaics. J. Am. Chem. Soc. 140, 3345-3351 (2018).

36. Hume-Rothery, W. \& Powell, H. M. On the theory of super-lattice structures in alloys. Z. Krist. 91, 23-47 (1935).

37. Luo, D. Y. et al. Enhanced photovoltage for inverted planar heterojunction perovskite solar cells. Science 360, 1442-1446 (2018).

38. Leijtens, T. et al. Stability of metal halide perovskite solar cells. Adv. Energy Mater. 5, 1500963 (2015).

39. Hayashi, S. \& Hayamizu, K. Accurate determination of NMR chemical-shifts in alkali-halides and their correlation with structural factors. Bull. Chem. Soc. Jpn. 63, 913-919 (1990).

40. Kresse, G. \& Furthmuller, J. Efficiency of ab-initio total energy calculations for metals and semiconductors using a plane-wave basis set. Comput. Mater. Sci. 6, 15-50 (1996).

41. Kresse, G. \& Furthmuller, J. Efficient iterative schemes for ab initio total-energy calculations using a plane-wave basis set. Phys. Rev. B 54, 11169-11186 (1996).

42. Perdew, J. P., Burke, K. \& Ernzerhof, M. Generalized gradient approximation made simple. Phys. Rev. Lett. 77, 3865-3868 (1996).

43. Van de Walle, A. et al. Efficient stochastic generation of special quasirandom structures. Calphad 42, 13-18 (2013).

\section{Acknowledgements}

This work was funded by National Science Foundation of China (number 51502224 and 51972255), the financial support from Chinese Scholarship Council (CSC). D.J.K., A.H., and L.E. acknowledge support from Swiss National Science Foundation Grant Number 200021_160112.

\section{Author contributions}

W.X. conceived the idea of the work. W.X. and Z.W. designed the project. W.X. fabricated and characterized devices, performed PL, UV-vis, and stability. D.J.K. and L.E. carried out the solid-state NMR characterization and analyzed the resulting data. W.T. performed EL measurement and analyze the resulting data. W.X., Z.W., and J.L. carried out SEM imaging. W.X. and J.L. performed the XRD measurements. A. Hofstetter carried out DFT calculations of the NMR parameters. W.X. and Z.W. performed the XPS measurements and analyzed the XRD and SEM data. J.Z., W.X., and Z.W. performed PL measurements and analyzed the resulting data. L.Z. and X.W. performed the firstprinciples calculations. W.X. and Z.W. wrote the manuscript. D.J.K., W.T., L.E.M.G., and A. Hagfeldt revised the manuscript. All the authors contributed to the final manuscript preparation.

\section{Competing interests}

The authors declare no competing interests.

\section{Additional information}

Supplementary information is available for this paper at https://doi.org/10.1038/s41467 019-12678-5.

Correspondence and requests for materials should be addressed to W.X. or A.H.

Peer review information Nature Communications thanks the anonymous reviewer(s) for their contribution to the peer review of this work.

Reprints and permission information is available at http://www.nature.com/reprints

Publisher's note Springer Nature remains neutral with regard to jurisdictional claims in published maps and institutional affiliations.

Open Access This article is licensed under a Creative Commons Attribution 4.0 International License, which permits use, sharing, adaptation, distribution and reproduction in any medium or format, as long as you give appropriate credit to the original author(s) and the source, provide a link to the Creative Commons license, and indicate if changes were made. The images or other third party material in this article are included in the article's Creative Commons license, unless indicated otherwise in a credit line to the material. If material is not included in the article's Creative Commons license and your intended use is not permitted by statutory regulation or exceeds the permitted use, you will need to obtain permission directly from the copyright holder. To view a copy of this license, visit http://creativecommons.org/ licenses/by/4.0/.

(C) The Author(s) 2019 